\title{
Mentoring Relationships Experienced by Urban Indian Youth- Do These Matter? : An Exploratory Study
}

\author{
Priya Singh ${ }^{1}$, Seema Mehrotra ${ }^{2}$ \\ ${ }^{1}$ Ex. Clinical Psychology Scholar, NIMHANS, Bangalore and Clinical Psychologist, Hyderabad. \\ ${ }^{2}$ Professor of Clinical Psychology, NIMHANS, Bangalore, Karnataka. \\ Email: drmehrotra_seema@yahoo.com \\ Corresponding author: Seema Mehrotra
}

\begin{abstract}
Introduction: The beneficial impact of mentoring relationships in the lives of youth has been well documented. However a bulk of this literature is about youth at risk and most studies pertain to examination of outcomes of formal mentoring programs. There is a significant dearth of studies on mentoring relationships experienced by urban Indian youth in the general community. The present study explored the availability of mentoring relationships, satisfaction with the same and its association with indices of well being and positive youth development in a sample of urban Indian youth.

Methodology: One hundred and eighty two youth in 17-30 years of age range were sampled from a metropolitan city in South India. A mentoring relationship survey along with standardized measures of psychological well being and self esteem as well as items on positive youth development indicators were used.

Results: Forty five percent of the sampled youth reported current availability of a mentoring relationship. Majority of these relationships involved informal mentoring. Youth who reported availability of a mentor had higher levels of psychological well being and were more likely to report better emotional health, perceived support and more engagement in helpful/service oriented activities than their counterparts. Providing motivation and inspiration to the mentees to do their best, freedom to share experiences and guidance to do something that mentee wanted were some of the most commonly endorsed mentoring functions.

Conclusion: Mentoring relationships serve multiple functions for urban Indian youth. The findings have implications for development and strengthening of mentoring initiatives for urban Indian youth.
\end{abstract}

Key Words: Mentoring, natural mentoring, urban India, youth mentoring, well- being.

(Paper received $-7^{\text {th }}$ May 2017, Peer review completed $-4^{\text {th }}$ June 2017 , Accepted $-9^{\text {th }}$ June 2017)

\section{INTRODUCTION}

Research suggests that relationships with non-family adults as well as extended family members apart from parents and siblings can play a vital role in the development of adolescents and young adults [1]. This line of research highlights the role of mentoring relationships in the lives of youth. Mentoring in general is defined as 'a relationship between an older, more experienced adult and an unrelated, younger protégé-a relationship in which the adult provides ongoing guidance, instruction, an encouragement aimed at developing the competence and character of the protégé [2]. Formal mentoring is relatively structured and is assisted by an organized service or organization and typically involves screening, training an ongoing support for the mentors. On the other hand, informal mentoring, also referred to as natural mentoring is said to involve a relationship between a caring individual and younger person, which is formed 
spontaneously during the course of regular life events, and in which the older person takes a special interest in the younger person and provides guidance and support $[3,4]$. Natural mentors are also referred to as 'concerned adults whom youth encounter informally in their social networks' [5].

It has been proposed that mentoring affects youth through three interrelated processes $[1,6]$ (a) by enhancing youth's social relationships and emotional well-being, (b) by improving their cognitive skills through instruction and conversation, and (c) by promoting positive identity development through serving as role models and advocates. These processes are likely to interact with each other over time. Mentoring has been seen as a facilitator of positive youth development (PYD) and wellbeing. Positive youth development is defined as an approach to promoting a set of guidelines on how a community can support its young people so that they can grow up competent and healthy and develop to their full potential [7]. Competence, confidence, caring, connection, and character are considered as the five $\mathrm{C}$ that comprise PYD [8].

Studies in a variety of settings and contexts have documented multiple benefits of high quality mentoring relationships. Some of these benefits that have been examined include lowered stress and depressive symptoms, lower engagement in risky behaviors, higher goal-orientation, self-control, educational aspirations and achievement, better social skills, improved self-esteem, well-being and career development. [9-12]

\section{RATIONALE AND AIMS OF THE PRESENT STUDY}

A scan at the available research suggests that a bulk of the mentoring research has originated in the West and most of it pertains to evaluation of formal mentoring programs. Moreover several of these studies have focused on only a segment of youth, i.e. youth at-risk, and rates of engagement in different kinds of problem behaviors and academic engagement have been some of the most commonly examined outcomes. [4] There are very few studies on the extent to which youth, who are not selected for their elevated riskstatus, experience a mentoring relationship in their natural context and the nature of functions that mentoring serves in this context. Cultural factors can play an important role in the experience of mentoring relationships with non family adults and the functions served by such relationships [13].There is a scarcity of studies from India on the association between availability of mentoring relationships and indices of psychological wellbeing and positive youth development.

In this backdrop, the present study was aimed at a) documenting the extent to which urban Indian youth report availability of a mentoring relationship, and b) examining differences in well-being and positive youth development indices between youth who reported presence of current mentoring relationship vs those who did not report a current mentoring relationship. In addition, the study also attempted to examine the association of current mentoring relationship satisfaction with well-being indices. The present study focused on mentoring relationships as experienced by youth within 17 to 30 years of age range.

\section{METHODOLOGY}

\section{Design}

The study used a cross sectional exploratory survey design.

\section{Sample}

The study sample included student as well as working youth within the age range of 17 to 30 years. The participants had to be able to respond to the questionnaires in English. A quota sampling approached was used with the plan to recruit 60 participants (with roughly equal representations of both genders) in the following three age groups: 17-20 years; $21-25$ years and 26-30 years. The student sample was recruited from three educational institutions and youth were drawn from varied courses spanning arts, science, management and commerce streams within each of these institutions, subject to availability of permission from authorities and consent from individual participants. An attempt was made to enroll at least one-third of working youth between 21-30 years age range. Working sample was recruited through contacting working professionals in multiple settings, using snow ball sampling approach. 


\section{Tools used in the study}

Basic data sheet: This was prepared to gather basic data relevant to study, e.g. age, gender, religion, marital status, occupational status, educational qualification, family type, current living arrangement etc. Quality of current relationship with each parent was enquired using a 4-point response format (not close/ close but with frequent conflicts, close but occasional conflicts/ close with rare conflicts). Presence or absence of current, close and satisfying relationship with any sibling and any grandparent was asked using a dichotomous yes/no type of item. Use of any addictive substances in the past six months was also inquired through a single checklist type item (alcohol, smoking cigarettes, and any other addictive drug).

Mentoring Relationship Survey: This was developed for the present study. It included likert type ratings, multiple choice items as well as open ended items. The items in this survey relevant to the present study are described here. Availability of a mentoring relationship currently, mentor characteristics, and satisfaction with the current mentoring relationship were explored. The availability of a mentor figure currently was asked using a single item with a yes/no format. In order to ensure uniformity in understanding the meaning of the term 'mentor', this question was preceded by a simple definition of a mentor as follows: "A mentor is a person in your life who is older than you, who supports you and guides you. This person is someone you look up to and you feel like he/she cares about you. Please note that the person you name as your mentor should not be your parent, own brother/sister/grandparent. If you have more than one person whom you can call as your mentor, chose one person with whom you share the closest relationship for answering the questions that follow." Formal or informal nature of the mentoring was ascertained by asking whether the mentor was officially/formally assigned to the participant as a mentor by an institution/organization/agency. A few basic characteristics of the mentor (e.g. age range, education level, work status etc.) were asked using multiple choice questions. Satisfaction with the current mentoring relationship was inquired into, using a single item with a 3 point response format (on the whole not satisfactory/ somewhat satisfactory/ satisfactory to a large extent).

The nature of functions being served/needs being met through the current mentoring relationships was assessed through 12 items. These items were developed based on available literature on the common needs/functions served though mentoring relationship.The items were further modified based on feedback from a panel of 3 experts who were mental health professionals with experience in the field of youth development. A response format ranging from 'rarely' to 'very often' was utilized along with the initial question asking the participants as to what they felt they received from their current mentoring relationship. Content-based subscales were formed by grouping 6 items each under two categories. The items with an explicit focus on motivating, inspiring and providing emotional support (e.g. receiving emotional comfort when I am upset) were grouped under the subscale "emotional-motivational". The items focusing on provision of information, guidance etc. was grouped under the subscale named as "information-guidance" (e.g. helpful information about things/people/opportunities). These two subscales exhibited internal consistency reliabilities of 0.72 and 0.73 respectively and had normal distribution of scores.

\section{Well-being indices}

1. Self-esteem scale [14] is a brief ten item simple measure that uses four point likert type ratings to provide an overall index of level of self esteem. The measure had an internal consistency reliability of 0.79 in the present study sample.

2. Psychological well being scale: It is a 20 item measure that has evolved from a version of Ryff's measures and it was tested through a large scale survey of Indian young adults within 20-35 years of age range [15]. It has good internal consistency, factorial and concurrent validity. Factor analysis in the Indian youth sample has indicated four factorially derived subscales: sense of engagement and growth, positive relationships with others, self acceptance and sense of mastery and competence. Subscales scores as well as an overall well being scores can be derived through 
the use of this measure. The internal consistency reliability of this measure was satisfactory with the overall scale reliability being 0.89 in the study sample and the subscale reliabilities ranging between 0.76 and 0.81 .

3. Positive youth development: Positive Youth Development (PYD) Benchmark questions [16] were used in the present study after minor modifications in wordings to suit the sample. These consists of six questions covering perceived physical and emotional health (5 point response format from 'excellent' to 'poor') and 4 PYD attributes namely, competence, confidence, support and service (4-point response format from 'very much true' to 'not at all true') as indicators of positive youth development.

\section{Procedure}

The study was carried out after obtaining approval from the parent department of the researchers for its scientific and ethical aspects. Data collection was carried out only on those participants who provided the investigator with written informed consent. Investigator was present during the administration of the tools. For student participants, the measures were administered in small groups of 10-30 individuals. Participants were provided with clarification wherever needed. The investigator ensured that the participants respond to each item in the questionnaire. It took around 45 minutes for the participants to complete the questionnaires. The working youth were met individually or in small groups of 3-5 individuals to seek informed consent and they were explained about filling up of the questionnaires. Most of them returned the filled questionnaires within a week, while a few completed and returned the same in the first meeting itself. They were asked to clarify any doubts with the investigator while returning the questionnaires.

\section{RESULTS}

\section{Sample characteristics}

The sample comprised of 182 participants from the community (various colleges and work places) in a metropolitan city in South India. There was an equal representation of participants across age groups (17$20,21-25$ and $26-30$ years). Both the genders were equally represented. In line with the sampling plan, about two-third of the participants were student youth and one-third were working youth. About $28 \%$ had 12 years of formal education. A majority were Hindu by religion, single, hailing from nuclear family and staying with family/relatives. About one third were staying in hostel or other similar arrangements. (Table 1) Almost two third of the participants sampled reported not using any addictive substances in the past 6 months. About $39-45 \%$ of the sampled youth reported close relationship with rare conflicts; while $10-17 \%$ reported frequent conflicts despite a close relationship with father and mother respectively and about $3 \%$ reported lack of a close relationship with any parent. About $28 \%$ and $46 \%$ of the youth indicated absence of a close satisfying relationship with any sibling and any grandparent respectively.

\section{Availability of mentoring relationship and characteristics of mentors}

Eighty one out of 182 study participants (45\%) reported having a current mentoring relationship as defined in the survey questionnaire. This group was compared with the group reporting non-availability of a mentoring relationship currently. There were no differences between these two groups on age, gender, working status, marital status, educational level, religion or living condition. However, the two groups differed significantly on family type. A smaller proportion of those staying in non-nuclear family reported having a mentor-figure (Table 2).

Only a small minority (18\%) indicated that they had a formally assigned mentor while a large proportion of those who reported having a current mentor-figure currently available characterized their mentoring relationship as an informal one. Majority of the 81 mentored participants reported that the current mentor was either a relative or someone from the workplace. Typically, the current mentor was a working adult in the age range of 20-40 years, of either gender, with at least graduate level qualification (Table 3). 


\section{Nature of mentoring relationship and functions served}

The frequency of contact and nature of initiative with the current mentor were also explored. From table 4, it is evident that face to face contact with current mentor-figure happened either on a daily basis or at least on once a week basis in the majority cases. While in the case of phone or mail contact, the commonest frequency of contact was reported to be once or twice a month, followed by daily or once a week contact. This indicates frequent contact between the mentor and mentee through diverse means. Contact- initiation was from both sides (mentor and mentee) in bulk of the cases.

The 12- item mentoring relationship survey provided an opportunity to understand the extent to which the mentoring relationship served various functions. In majority of current mentoring relationships, the participants received motivation and inspiration to do their best; this was closely followed by freedom to share their experiences. Other frequently endorsed functions included guidance to do something mentees wanted, recognizing qualities as a person and providing emotional comfort when upset (Table 5).

In terms of satisfaction with the overall quality of current mentor relationship, majority of the participants reported being largely satisfied with the current mentoring relationship. A very small proportion $(2.46 \%)$ of the participants reported that they were not satisfied with the current mentoring relationship while about a quarter reported a modest level of satisfaction (Table 6).

\section{Mentoring, wellbeing and positive youth development}

The differences in the wellbeing of the participants who had a current mentor were compared to those who did not report having a current mentor. There was a significant difference in the overall psychological wellbeing scores and its two subscales, namely: sense of self-acceptance and sense of engagement and growth, with the mentor-available subgroup scoring higher on these variables. A similar trend of difference was seen on self-esteem (Table 7). Moreover, scores on information-guidance and emotional-support mentoring functions were positively associated with self-esteem $(r=0.22$ and $0.26, p>0.05)$.

Analysis using pattern of responses on the benchmark questions on positive youth development revealed that a significantly larger proportion of participants with mentors scored high (items marked as 'excellent/very good/good' OR 'very much true/pretty much true') on the three out of six indicators of positive youth development (PYD) namely, perceived emotional health, perceived support (presence of a caring adult) and service (self-reported helpful behaviours) (Table 8).

Though substance use was reported only by a small proportion of the participants in the study, $(n=39)$, about $10 \%$ in the currently mentored group and $32 \%$ in the non-mentored group reported using one or more substances. From yet another angle, 31 out of the 39 participants reporting use of addictive substances belonged to the non-mentored group. The association between self-reported use of addictive substance and presence/absence of mentoring relationship was significant $\left(X^{2}=11.8, p<0.01\right)$.

Satisfaction with current mentoring relationship was positively associated with information- guidance functions as well as emotional support received in mentoring relationships. Higher satisfaction with the current mentoring relationship was also significantly correlated with higher self-esteem, overall psychological well-being and with two of its subscales, namely sense of mastery and competence and positive relationships with others (Table 9).

\section{DISCUSSION}

This is perhaps one of the first few studies in urban India that explored the availability of mentors in an unselected community sample of youth within 17-30 years of age range. Both student and working youth were represented in the study.

It was observed that less than half of the sampled youth reported having a mentor figure in their life currently. In the group of youth who reported having a mentor, in more than three fourth of instances, they referred to an informal /natural mentoring relationship. Earlier literature has postulated that informal mentoring may be considered a normative process in the lives of young adults. [12] For example, it has been noted in previous studies that $75 \%-80 \%$ of youth have an informal mentor [17]. However, the present 
Table 1 - Sample characteristics: Socio-demographic details ( $\mathrm{N}=182)$

\begin{tabular}{|c|c|c|}
\hline Variables & Frequency & Percentage \\
\hline \multicolumn{3}{|c|}{ Age (years) } \\
\hline $17-20$ & 60 & 33 \\
\hline $21-25$ & 60 & 33 \\
\hline $26-30$ & 62 & 34 \\
\hline \multicolumn{3}{|c|}{ Gender } \\
\hline Male & 89 & 48.9 \\
\hline Female & 93 & 51.1 \\
\hline \multicolumn{3}{|c|}{ Education } \\
\hline $12^{\text {th }} \mathrm{Std}$ & 50 & 27.5 \\
\hline Graduate & 64 & 35.1 \\
\hline Postgraduate and above & 68 & 37.4 \\
\hline \multicolumn{3}{|c|}{ Working status } \\
\hline Student & 119 & 65.5 \\
\hline Working & 63 & 34.5 \\
\hline \multicolumn{3}{|c|}{ Marital status } \\
\hline Single & 146 & 80.2 \\
\hline Married & 36 & 19.8 \\
\hline \multicolumn{3}{|c|}{ Religion } \\
\hline Hindu & 131 & 72 \\
\hline Muslim & 16 & 8.8 \\
\hline Christian & 32 & 17.6 \\
\hline Others & 3 & 1.6 \\
\hline \multicolumn{3}{|c|}{ Family type } \\
\hline Nuclear & 142 & 78 \\
\hline Non-nuclear & 40 & 22 \\
\hline \multicolumn{3}{|c|}{ Current living condition } \\
\hline With family/relatives & 118 & 64.8 \\
\hline Hostel/PG & 57 & 31.4 \\
\hline Others & 7 & 3.8 \\
\hline
\end{tabular}

study findings suggests that although mentoring relationships, as defined in the present study, are fairly common, these are perhaps not available to a significant proportion of urban Indian youth. This may be a likely scenario in metropolitan cities in India that have witnessed significant rural to urban migration related to education and employment [18] which can pose challenges to experience social support and integration. Also, mentoring relationships can play a vital role in individuals who may not be experiencing close and satisfying relationship with parents/siblings or a grandparent as was the case in a sizable minority of the sampled participants. This in turn indicates the potential scope for formal mentoring programs as well as initiatives that strengthen informal mentoring opportunities in urban India as part of universal positive youth development and mental health promotion efforts. Going by the huge body of available research across the globe, mentoring could be considered a key tool for facilitating healthy development, decreasing distress and suicides and promoting youth mental health in a country like India which is witnessing a youth bulge and has documented high prevalence of common mental health concerns in the general population of youth $[19,20]$. However, for a large scale impact to be evident, this would require significant synergistic investment of efforts and sustained commitment on part of the researchers, policy makers, public, private sector and non government organizations as well as use of innovative ways to engage with the youth and their relational networks including potential mentors. 
Table 2 - Current availability of a mentor: association with socio-demographic variables

\begin{tabular}{|c|c|c|c|}
\hline VARIABLES & Mentor Available $(\mathrm{N}=81)$ & Mentor Not Available (N=101) & $\chi^{2}$ \\
\hline \multicolumn{4}{|c|}{ AGE (years) } \\
\hline $17-20$ & $48.33 \%$ & $51.67 \%$ & \multirow[t]{3}{*}{0.801} \\
\hline $21-25$ & $45 \%$ & $55 \%$ & \\
\hline $26-30$ & $40.32 \%$ & $59.68 \%$ & \\
\hline \multicolumn{4}{|c|}{ GENDER } \\
\hline Male & $44.94 \%$ & $55.06 \%$ & \multirow[t]{2}{*}{0.014} \\
\hline Female & $44.09 \%$ & $55.91 \%$ & \\
\hline \multicolumn{4}{|c|}{ EDUCATION } \\
\hline $12^{\text {th }} \mathrm{Std}$ & $46 \%$ & $54 \%$ & \multirow[t]{3}{*}{0.064} \\
\hline Graduate & $43.8 \%$ & $56.2 \%$ & \\
\hline Postgraduate and above & $44.1 \%$ & $55.9 \%$ & \\
\hline \multicolumn{4}{|c|}{ WORKING STATUS } \\
\hline Working & $46 \%$ & $54 \%$ & \multirow[t]{2}{*}{0.091} \\
\hline Student & $43.7 \%$ & $56.3 \%$ & \\
\hline \multicolumn{4}{|c|}{ MARITAL STATUS } \\
\hline Single & $45.2 \%$ & $54.8 \%$ & \multirow[t]{2}{*}{0.146} \\
\hline Married & $41.7 \%$ & $58.3 \%$ & \\
\hline \multicolumn{4}{|c|}{ FAMILY TYPE } \\
\hline Nuclear & $48.6 \%$ & $51.4 \%$ & \multirow[t]{2}{*}{$4.37^{*}$} \\
\hline Non-nuclear & $30 \%$ & $70 \%$ & \\
\hline \multicolumn{4}{|c|}{ CURRENT LIVING CONDITION } \\
\hline With family/relatives & $45.8 \%$ & $54.2 \%$ & \multirow[t]{2}{*}{0.215} \\
\hline Hostel/PG/others & $42.2 \%$ & $57.8 \%$ & \\
\hline
\end{tabular}

(All statistics done using Chi Square test* $\mathrm{p}<0.05$ )

As mentioned earlier, a large bulk of research has been on formal mentoring relationships. However, it is being increasingly recognized that youth form relationships with non-family adults in their natural contexts and these mentoring relationships serve a significant purpose in overall youth development and not merely protective functions for youth at risk [12].

Two subgroups were formed in the present study based on current availability of mentor and these were compared on basic socio-demographic variables. No significant association was found between current availability of mentor and various socio-demographic groups based on age, gender, educational level, working status and current living condition. This seems understandable as in the present study, most of the mentorships were informal in nature and almost all subgroups may have had similar opportunities to find a natural mentor. However, there was a significant association between current availability of mentor and family type. In case of the participants coming from nuclear families, almost an equal number of them either had a mentor or didn't have a mentor while in case of the participants from non-nuclear family; a majority (70\%) did not report having a mentor, as operationally defined. Relationships with parents and siblings as well as same age peers were excluded in the present study. It is plausible that the participants coming from the joint family system were less likely to form relationship with a prospective mentor figure owing to their psychosocial needs being met in the circle of older adults, including grandparents within the family itself. This is also in line with the observations that in several instances, when the present study participants did report having mentors, a significant proportion of them were relatives. Although older siblings and grandparents were excluded, relatives were not excluded in the definition of mentors, keeping in view the interdependent and collectivistic nature of the cultural context [21]. Several studies emphasize that the relatives do take up the role of natural mentor-like figures for the young people and the young people seem to benefit from these ties $[5,9]$. In the present study, teachers were also likely to be seen as mentors even if they are not assigned a formal mentorship status [5] 
Table 3 - Descriptions about the current mentor $(\mathrm{N}=81)$

\begin{tabular}{|c|c|c|}
\hline & Frequency & Percentage \\
\hline \multicolumn{2}{|c|}{ Identity of the mentor } \\
\hline Relative & 25 & 30.86 \\
\hline Neighbour & 6 & 7.41 \\
\hline Someone in the workplace & 23 & 28.39 \\
\hline Senior from college/school & 3 & 3.70 \\
\hline A teacher & 10 & 12.36 \\
\hline Any other & 14 & 17.28 \\
\hline \multicolumn{3}{|c|}{ Status } \\
\hline Formal & 14 & 17.28 \\
\hline Informal & 67 & 82.72 \\
\hline \multicolumn{3}{|c|}{ Age } \\
\hline $20-30$ & 31 & 38.27 \\
\hline $30-40$ & 31 & 38.27 \\
\hline $40-50$ & 12 & 14.82 \\
\hline 50 and above & 7 & 8.64 \\
\hline \multicolumn{3}{|c|}{ Occupation } \\
\hline Student & 10 & 12.36 \\
\hline Homemaker & 2 & 83.95 \\
\hline Working & 68 & 1.23 \\
\hline Retired & 1 & 2.46 \\
\hline \multicolumn{3}{|c|}{ Education } \\
\hline $10^{\text {th }}$ Std & 2 & 44.45 \\
\hline $12^{\text {th }}$ Std & 4 & 48.15 \\
\hline Graduate & 36 & \\
\hline Postgraduate and above & 39 \\
\hline
\end{tabular}

Table 4 - Frequency of contact and nature of initiative with current mentor $(\mathrm{N}=\mathbf{8 1})$

\begin{tabular}{|c|c|c|}
\hline Frequency of contact & Frequency & Percentage \\
\hline \multicolumn{2}{|c|}{ In Person } \\
\hline Everyday/once a week & 27 & 33.33 \\
\hline Once/more than once in a month & 27 & 33.33 \\
\hline A few times in 3-6 month & 11 & 13.58 \\
\hline Once/twice in a year & 13 & 16.05 \\
\hline Never met/hardly met Phone/mail \\
\hline \multicolumn{2}{|c|}{3} \\
\hline Everyday/once a week & 33 \\
\hline Once/more than once in a month & 42 & 3.71 \\
\hline A few times in 3-6 months & 4 & 40.74 \\
\hline Once/twice in a year & 2 & 4.96 \\
\hline \multicolumn{2}{|c|}{ Contact initiation } \\
\hline Myself & 16 & 2.46 \\
\hline My mentor & 5 & 19.75 \\
\hline Both of us in turns & 60 & 74.08 \\
\hline
\end{tabular}

The functions frequently served by mentoring relationships in the present study included both instrumental and emotional-support functions that have been found to be important aspects of mentoring relationships [5, 12]. In the present study, currently-mentored and non-mentored groups differed significantly in psychological well being and positive youth development indicators. 
Table 5 - Experiences with current mentor (What I receive)

\begin{tabular}{|c|c|c|c|c|c|c|c|c|}
\hline \multirow{2}{*}{$\begin{array}{c}\text { Received from current } \\
\text { mentor }\end{array}$} & \multicolumn{2}{|c|}{ Very often } & \multicolumn{2}{c|}{ Often } & \multicolumn{2}{c|}{ Sometimes } & \multicolumn{2}{c|}{ Rarely } \\
\cline { 2 - 9 } & Freq & $\%$ & Freq & $\%$ & Freq & $\%$ & Freq & $\%$ \\
\hline $\begin{array}{c}\text { Information about } \\
\text { things/people/opportunities }\end{array}$ & 24 & 29.62 & 38 & 46.91 & 18 & 22.22 & 1 & 1.23 \\
\hline Guidance & 28 & 34.57 & 28 & 34.57 & 22 & 27.16 & 3 & 3.70 \\
\hline Spending time together & 12 & 14.81 & 15 & 18.52 & 17 & 20.99 & 37 & 45.68 \\
\hline $\begin{array}{c}\text { Helping in problem } \\
\text { solving/conflict resolution }\end{array}$ & 22 & 27.16 & 29 & 35.81 & 23 & 28.39 & 7 & 8.64 \\
\hline $\begin{array}{c}\text { Helping in taking right } \\
\text { decision }\end{array}$ & 16 & 19.76 & 45 & 55.56 & 18 & 22.22 & 2 & 2.46 \\
\hline $\begin{array}{c}\text { Receiving emotional } \\
\text { comfort when distressed }\end{array}$ & 25 & 30.87 & 24 & 29.62 & 14 & 17.28 & 18 & 22.23 \\
\hline $\begin{array}{c}\text { Motivating/inspiring to do } \\
\text { my best }\end{array}$ & 39 & 48.15 & 24 & 29.62 & 12 & 14.82 & 6 & 7.4 \\
\hline $\begin{array}{c}\text { Clarifies goals/priorities } \\
\text { Helps in connecting to } \\
\text { others/build social network }\end{array}$ & 24 & 29.62 & 32 & 39.53 & 24 & 29.62 & 1 & 1.23 \\
\hline $\begin{array}{c}\text { Approves/recognizes my } \\
\text { qualities }\end{array}$ & 28 & 34.57 & 30 & 37.03 & 19 & 23.46 & 4 & 4.94 \\
\hline $\begin{array}{c}\text { Freedom to share } \\
\text { experiences }\end{array}$ & 38 & 46.91 & 26 & 32.09 & 15 & 18.53 & 2 & 2.47 \\
\hline $\begin{array}{c}\text { Listens without } \\
\text { judging/criticizing }\end{array}$ & 23 & 28.39 & 43 & 53.10 & 14 & 17.28 & 1 & 1.23 \\
\hline
\end{tabular}

Table 6 - Overall quality of relationship with current mentor

\begin{tabular}{|c|c|c|}
\hline & Frequency & Percentage \\
\hline Not Satisfactory & 2 & 2.46 \\
\hline Somewhat satisfactory & 17 & 20.99 \\
\hline To a large extent satisfactory & 62 & 76.55 \\
\hline
\end{tabular}

Table 7 - Differences in the wellbeing between subgroups with/without current availability of mentor

\begin{tabular}{|c|c|c|c|c|c|}
\hline \multirow{2}{*}{ Well-being variables } & \multicolumn{2}{|c|}{$\begin{array}{c}\text { Mentor Available } \\
\text { subgroup (N=81) }\end{array}$} & \multicolumn{2}{c|}{$\begin{array}{c}\text { Mentor Not available } \\
\text { subgroup (N=101) }\end{array}$} & $\begin{array}{c}\text { t /Mann } \\
\text { Whitney ' } \mathbf{~} \\
\text { ' }\end{array}$ \\
\cline { 2 - 5 } & Mean & SD & Mean & SD & \\
\hline Self Esteem & 20.49 & 4.18 & 19.33 & 4.47 & 1.77 \\
\hline Psychological well being & 91.70 & 14.81 & 85.81 & 18 & $2.37^{*}$ \\
\hline \multicolumn{7}{|c|}{ Psychological wellbeing sub scales } \\
\hline Self-acceptance & 20.44 & 2.92 & 18.44 & 4.40 & $3.17^{\text {a** }}$ \\
\hline $\begin{array}{c}\text { Sense of mastery and } \\
\text { competence }\end{array}$ & 23.63 & 6.68 & 22.13 & 6.99 & 1.47 \\
\hline $\begin{array}{c}\text { Positive relationships with } \\
\text { others }\end{array}$ & 21.70 & 6.16 & 21.11 & 6.31 & $0.68^{\text {a }}$ \\
\hline $\begin{array}{c}\text { Sense of engagement and } \\
\text { growth }\end{array}$ & 25.93 & 3.70 & 24.14 & 4.86 & $2.35^{\text {a* }}$ \\
\hline
\end{tabular}

(Statistics done using $\mathrm{t}$ test and Mann Whitney $\mathrm{U}$ test ${ }^{*} \mathrm{P}<0.05,{ }^{*} \mathrm{P}<0.01$; ${ }^{\mathrm{a}}$ Mann Whitney $\mathrm{U}$ values) 
Table 8 - Differences in the positive youth development indicators between subgroups with/without current availability of mentor

\begin{tabular}{|c|c|c|c|}
\hline Positive youth development indicators & $\begin{array}{l}\text { Mentoring } \\
\text { Available } \\
\text { subgroup }\end{array}$ & $\begin{array}{l}\text { Mentoring not } \\
\text { available } \\
\text { subgroup }\end{array}$ & $\chi^{2}$ \\
\hline \multicolumn{4}{|c|}{ Perceived physical health } \\
\hline High & $84 \%$ & $89 \%$ & \multirow[t]{2}{*}{1.05} \\
\hline Low & $16 \%$ & $10.9 \%$ & \\
\hline \multicolumn{4}{|c|}{ Perceived emotional health } \\
\hline High & $77.8 \%$ & $43.6 \%$ & \multirow[t]{2}{*}{$21.72^{* *}$} \\
\hline Low & $22.2 \%$ & $56.4 \%$ & \\
\hline \multicolumn{4}{|c|}{ Perceived competence } \\
\hline High & $93.8 \%$ & $93.1 \%$ & \multirow{2}{*}{0.04} \\
\hline Low & $6.2 \%$ & $6.9 \%$ & \\
\hline \multicolumn{4}{|c|}{ Perceived confidence } \\
\hline High & $82.7 \%$ & $84.2 \%$ & \multirow[t]{2}{*}{0.07} \\
\hline Low & $17.3 \%$ & $15.8 \%$ & \\
\hline \multicolumn{4}{|c|}{ Perceived support } \\
\hline High & $69.1 \%$ & $42.6 \%$ & \multirow[t]{2}{*}{$12.78^{* *}$} \\
\hline Low & $30.9 \%$ & $57.4 \%$ & \\
\hline \multicolumn{4}{|c|}{ Perceived service } \\
\hline High & $79 \%$ & $46.5 \%$ & \multirow{2}{*}{$19.93^{* *}$} \\
\hline Low & $21 \%$ & $53.5 \%$ & \\
\hline
\end{tabular}

(Statistics done using Chi Square test ${ }^{* *} \mathrm{p}<0.01$ )

Table 9 - Satisfaction with current mentoring relationship - Correlates

\begin{tabular}{|c|c|}
\hline Variables & $\begin{array}{c}\text { Satisfaction with current mentoring } \\
\text { relationship }\end{array}$ \\
\hline \multicolumn{2}{|c|}{ Mentoring function received } \\
\hline Information-guidance received & $0.35^{* *}$ \\
\hline Emotional-support received & $0.56^{* *}$ \\
\hline \multicolumn{2}{|c|}{ Well-being indices } \\
\hline Self-esteem & $0.33^{* *}$ \\
\hline Psychological well being & $0.32^{* *}$ \\
\hline Psychological Well being sub scales \\
\hline Self-acceptance & 0.19 \\
\hline Sense of mastery \& competence & $0.24^{*}$ \\
\hline Positive relationships with others & $0.30^{* *}$ \\
\hline Sense of engagement and growth & 0.16 \\
\hline
\end{tabular}

$\left({ }^{*} \mathrm{p}<0.05,{ }^{* *} \mathrm{p}<0.01\right.$ Pearson's correlation used)

Currently mentored participants had significantly higher overall psychological well-being and higher scores on two subscales, namely, self-acceptance and, sense of engagement \& growth. They also had higher scores on three out of six positive youth development indicators (perceived emotional health, perceived support and service) in comparison to the currently non-mentored participants. As mentioned earlier, benefits to the mentees from the mentoring relationship in terms of psychological well being, self-esteem and educational outcomes etc have been reported across studies [9-12].

On examining correlations of the mentoring functions received with the well being indices, it was found that the self esteem was positively correlated with emotional-motivational and information-guidance received. Interactions with mentors can mobilize resources and opportunities and strengthen positive interactions which can facilitate identity development and experience of self esteem [22, 23]. 
The correlations of current mentoring relationship satisfaction and both the mentoring function (information-guidance and emotional-motivational) received were positive. This in turn meant that more the mentees received these functions through the mentoring relationships, the more they were satisfied with their relationship with the mentor. 'Emotional-motivational' function had stronger relationship with satisfaction in comparison to the 'information-guidance' function. It is important to note that satisfaction with one's current mentor was positively and significantly correlated with multiple indices of well-being namely: self-esteem, overall psychological well-being and positive relationships with others and sense of mastery and competence. Quality of mentoring relationship has been examined in several studies as an important moderator of the outcomes of mentoring [24].

Engagement in risky behaviors was not focused upon in the present study and was not documented in a systematic and thorough fashion. However the pattern of responses on a single item concerning current use of any addictive substances in the recent past threw up interesting observation that most of the sampled participants who reported use of substances in the recent six months belonged to the non-mentored group. Protective role of mentoring relationships have been well documented in youth samples $[9,11,25]$.

Mentoring functions received, as perceived by the participants seemed to impact satisfaction with the mentoring relationship. In turn, a satisfying relationship with the mentor appeared to go hand in hand with various well-being indicators. The overall pattern of findings in the present study raises the possibility that the influence of mentoring on well-being may be at least partly mediated by satisfaction with one's relationship with the mentor. This requires examination using larger scale studies, preferably those employing prospective study designs.

\section{Limitations}

The present study was exploratory in nature and examined difference in psychological well being and selfesteem between mentored and non-mentored youth. Positive youth Development indicators were examined using single self-report items that tapped perceived competence, confidence, support, availability and engagement in helpful acts/service to others. This was done in order to maintain respondent burden at a low level. It may be useful to include reports of significant others and incorporate a more detailed assessment of positive youth development. The replicability of the findings needs to be established in future studies using larger samples of youth across different cities and settings in urban India. It is plausible that youth better equipped with resources and higher levels of well being may be more likely than disadvantaged youth to have access to mentoring relationships. Longitudinal study designs can throw light on the potential bidirectional nature of association between mentoring and wellbeing variables.

\section{CONCLUSION}

Limitations notwithstanding, the present study highlights that a significant proportion of youth in urban Indian context may not have access to a mentoring relationship and those who do report currently experiencing such a relationship are likely to enjoy higher levels of psychological wellbeing, experience greater levels of self esteem and are also more likely to report better emotional health, perceived support and more engagement in helpful/service oriented activities. This is perhaps one of the few Indian studies on mentoring experiences that sampled student as well as working youth irrespective of their risk-status. It was observed that informal, natural mentoring relationships were much more common than formal mentoring relationships. The findings of the study have implications for development of mentoring programs for youth in India, improving the nature of existing formal mentoring programs in colleges/organizations as well as offering information to adults in general community who engage in informal mentoring relationships with youth.

\section{REFERENCES}

1. Rhodes JE, Ebert E, Fischer K. Natural mentors: An overlooked resource in the social networks of young, 
African American mothers. Am J Community Psychol 1992;20:445-61.

2. Rhodes JE. Stand by me: The risks and rewards of mentoring today's youth; Harvard University Press: Cambridge, MA 2004.

3. Jacobi M. Mentoring and undergraduate academic success: A literature review. Rev Educ Res 1991;61:50532.

4. Erickson LD, Mcdonald S, Elder GH. Informal mentors and education: Complementary or compensatory resources? Sociol Edu 2009; 82:344-67.

5. Kogan SM, Brody GH, Chen YF. Natural mentoring processes deter externalizing problems among rural African American emerging adults: A prospective analysis.Am J Community Psychol 2011;48:272-83.

6. Rhodes JE, Reddy R, Grossman JB. The Protective Influence of mentoring on adolescents' substance use: Direct and indirect pathways. Appl Dev Sci 2005; 9:31-47.

7. Dotterweich J. Positive Youth Development Resource Manual, Cornell University, ACT for Youth: Ithaca, NY, 2006.

8. Lerner RM. Positive Youth Development, participation in community youth development programs, and community contributions of fifth-grade adolescents: Findings from the First Wave of the 4-H Study of Positive Youth Development.. J Early Adolesc 2005; 25:17-71.

9. Hurd N, Zimmerman M. Natural mentors, mental health, and risk behaviors: A longitudinal analysis of African American adolescents transitioning into adulthood. Am J Community Psychol 2010;46:36-48.

10. Dubois DL, Silverthorn N. Natural mentoring relationships and adolescent health: Evidence from a national study. Am J Public Health 2005;95:518-24.

11. Gupta S, Jindal V, Gulati P, Walia DK, Sarpal SS. Effect of mentoring on psycho-social behavior, lifestyle, sexual behavior and health condition of professional students. J Psychol Psychother 2013;2:1.

12. McDonald S, Erickson LD, Johnson MK, Elder GH. Informal mentoring and young adult employment. Soc Sci Res 2007; 36:1328-347.

13. Ramaswami A, Dreher GF. Dynamics of mentoring relationships in India: A qualitative, exploratory study. Hum Resour Manage 2010; 49: 501-30.

14. Rosenberg, M. Society and the Adolescent Self-Image. Princeton University Press: Princeton 1965.

15. Mehrotra S, Tripathi R, Banu H. Psychological well-being: Reflections on an elusive construct and its assessment. J. Indian Acad Appl Psychol 2013; 39:189-95.

16. Nystrom RJ, Adirana P, Knipper RS. Measuring Positive Youth Development: The development of a State Benchmark. J Youth Dev 2008;3:Article 080301FA002.

17. Beam M, Chen C, Greenberger E. The nature of adolescents' relationships with their "Very Important" nonparental adults. Am J Community Psychol 2002;30:305-25.

18. Lusome R, Bhagat RB. Trends and Patterns of Internal Migration in India, 1971-2001. Annual Conference of Indian Association for the Study of Population (IASP), 7-9 June, 2006, Thiruvananthapuram. 2006. http://demografi.bps.go.id/phpFileTree/bahan/kumpulan_tugas_mobilitas_pak_chotib/Kelompok_1/Refe rens i/Lusome_and_Baghat_Trends_and_Patterns_of_Internal_Migration_in_India_1971-2001.pdf

19. Shukla R. Indian Youth: Demographics and Readership: Results from the National Youth Readership Survey. National Book Trust \& National Council of Applied Economic Research: New Delhi, 2010.

20. Gururaj G, Varghese M, Benegal V, Rao GN, Pathak K, Singh LK, Mehta RY, R.D., Shibukumar TM, Kokane A, Lenin Singh RK, Chavan BS, Sharma P, R., C, Dalal PK, Saha PK, Deuri SP, Giri AK, Kavishvar AB, Sinha VK, Thavody J, C.R., Akoijam BS, Das S, Kashyap A, Ragavan VS, Singh SK, M.R. and N. collaborators, Group.National Mental Health Survey of India, 2015-16: Summary, National Mental Health Survey of India. NIMHANS: Bangalore, 2016.

21. Zhang AY, Lonnie R, Snowden LR, Sue S. Differences between Asian and White Americans' help seeking and utilization patterns in the Los Angeles area. J Community Psychol 1998;26:317-26.

22. Darling N, Hamilton S, Toyokawa T, Matsuda S. Naturally occurring mentoring in Japan and the United States: Social roles and correlates. Am J Community Psychol 2002;30:245-70.

23. Bruce M, Bridgeland J. The mentoring effect: Young people's perspectives on the outcomes and availability of mentoring. Civic Enterprises with Hart Research Associates for MENTOR: The National Mentoring Partnership: Washington, D.C., 2014.

24. Whitney SD, Hendricker EN, Offutt CA. Moderating factors of natural mentoring relationships, problem behaviors, and emotional well-being. Mentoring \& Tutoring: Partnership in Learning 2011;19:83-105.

25. Beier SR, Rosenfeld WD, Spitalny KC, Zansky SM, Bontempo AN. The potential role of an adult mentor in influencing high-risk behaviors in adolescents. Arch Pediatr Adolesc Med 2000;154: 327-31.

Acknowledgements - Nil; Source of Funding - Nil; Conflict of Interest - Nil 